\title{
Verification of crop coefficients for chickpeas in the Mediterranean environment
}

\author{
P. Garofalo, A. V. Vonella, S. Ruggieri \& M. Rinaldi \\ Agricultural Research Council, \\ Research Unit for Cropping System in Dry Environments, Italy
}

\begin{abstract}
Crop coefficient $(K c)$ is the multiplier factor to estimate the actual from reference evapotranspiration; for many crops, also in consideration of changing cultivar and pedo-climatic conditions, a verification of $K c$ and length of different stages is important for a more precise irrigation scheduling. The aim of this research is to calculate crop coefficients for chickpeas cropped in Southern Italy, with water supply in order to obtain the best seed yield.

A field experiment was carried out on chickpeas sown in December in a 1 ha plot, where in the middle two weighing lysimeters were located. One irrigation at flowering was managed with $60 \mathrm{~mm}$ of water; the potential evapotranspiration was determined with the Penman-Monteith formula, whereas the effective daily water consumption was obtained by difference in the lysimeters weight. The $K c$ values measured at different crop stages were compared with those reported by Food and Agriculture Organization of the United Nations (FAO) paper n. 56.

The obtained results suggest that the initial stage length is approximately 80 days, and the relative $K c$ is 0.54 ; the development stage persists for 35 days. The mid-season stages took 40 days with a $K c$ of 0.97 . Finally, the late season stage persists for 35 days, with a $K c_{\text {end }}$ value equal to 0.29 .

From this work, we can update the $K c$ proposed by the FAO, and particularly give a greater value for $K c$ for the initial stage $(0.54$ vs 0.4$)$, while we can suggest a $K c_{\text {end }}$ lower than that reported by the FAO ( 0.29 vs 0.35$)$.

Keywords: cicer arietinum L., evapotranspiration, water requirement, FAO crop coefficient.
\end{abstract}




\section{Introduction}

The chickpea (Cicer arietinum L.) is one of the major legume crops cultivated in the Mediterranean region, thanks to its great adaptability to drought conditions, typical in this environment. Fig.1 shows that in the five years, from 2003 to 2007 , the areas under chickpea crop cultivation in the world increased, with seed production rising by about $29 \%$.

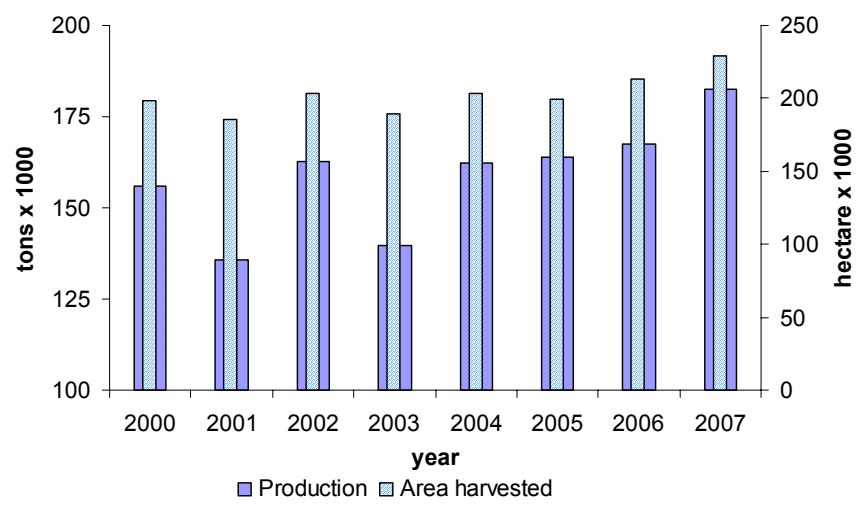

Figure 1: Chickpea world surface cultivation and seed yield (FAOSTAT [1]).

Limited supplemental irrigation can, however, play a major role in raising and stabilizing the productivity of winter-sown chickpeas [2]. Rinaldi et al. [3] reported as one irrigation during the flowering or seed filling stages determined the best result in term of seed yield. They also underlined a reduced amount of water at a specific phenological stage is preferable to a repeated water supply during the whole growth season, in order to avoid an unbalanced vegetative vs. reproductive plant organs growth.

The crop evapotranspiration and, consequently, the irrigation water requirement, can be estimated from meteorological data, as reported by the Food and Agriculture Organization of the United Nations (FAO) [4], with different reviews [5]. Today the basic approach to determine crop water requirement is to calculate the crop coefficient $(K c)$ as the ratio between the measured crop evapotranspiration $(E T m)$, obtained by weighing lysimeters and the reference evapotranspiration $\left(E T_{0}\right)$. Maximum crop evapotranspiration is referred to a crop under optimal soil water conditions, but, as we said before, in chickpeas, well watered conditions are not the optimal in order to obtain the highest seed productivity.

The reference evapotranspiration can be computed by several methods (Blaney-Criddle, Radiation, Pan evaporation, FAO modified Penman, etc.) [6], but when different climate variables are available, the Penman-Monteith formula is preferable, taking into account the specific resistance parameter of the crop. 
We choose the $K c$ single approach, because, as reported by the FAO Paper 56 [5], this is the best way to calculate water requirements in dry environments and for non-irrigated crops.

Crop coefficients are affected by plant growth and development, morphology and physiology, crop management, such as the irrigation regime and the pedoclimatic condition. For these reasons it is important to check the $K c$ values, for the different environment and different growth stages, building the crop coefficient curve close to the observed crop evapotranspiration data. Furthermore, in the FAO the lengths of the different crop stages of chickpeas are not reported.

The aims of this work are: i) to calculate the $K c$ and growth stage lengths for chickpeas and ii) to compare them with FAO suggested values.

\section{Material and methods}

The field experiment was carried out in 2006-2007 at Foggia (lat. 41 ${ }^{\circ} 7^{\prime \prime} \mathrm{N}$; long. $15^{\circ} 83^{\prime} 5^{\prime \prime} \mathrm{E}$, alt. $90 \mathrm{~m}$ a.s.1.) in Southern Italy. The soil is a vertisol of alluvial origin, Typic Calcixeret, (Soil Taxonomy $10^{\text {th }}$ edn, USDA 2006), siltyclay with the following characteristics: organic matter, $2.1 \%$; total $\mathrm{N}, 0.122 \%$; $\mathrm{NaHCO}_{3}$-extractable $\mathrm{P}, 41 \mathrm{ppm} ; \mathrm{NH}_{4} \mathrm{O}$ Ac-extractable $\mathrm{K}_{2} \mathrm{O}, 1598 \mathrm{ppm} ; \mathrm{pH}$ (water) 8.3; field capacity water content $0.396 \mathrm{~m}^{3} \mathrm{~m}^{-3}$; permanent wilting point water content $0.195 \mathrm{~m}^{3} \mathrm{~m}^{-3}$, available soil water $202 \mathrm{~mm} \mathrm{~m}^{-1}$. The climate is "'accentuated thermomediterranean", (Unesco-FAO classification), with temperatures below $0^{\circ} \mathrm{C}$ in the winter and above $40^{\circ} \mathrm{C}$ in the summer. Annual rainfall (mean $550 \mathrm{~mm}$ ) is mostly concentrated during the winter months and class "A pan" evaporation exceeds $10 \mathrm{~mm} \mathrm{day}^{-1}$ in summer. Daily meteorological data - temperatures, humidity, rainfall, wind velocity and solar radiation - were collected in the local meteorological station.

The weighing lysimeters are located in the middle of a $100 \times 100 \mathrm{~m}$ field area, to reduce the fetch influence. The lysimeters tank is made of steel, has a square shape with an area of $4 \mathrm{~m}^{2}(2 \times 2 \mathrm{~m})$ and a depth of $1.5 \mathrm{~m}$, fully placed into the soil and without contact with the surrounding soil (Figure 2). The soil in the tank was placed in 2001 according to soil stratigraphy. In the bottom of the tank a drainage system to collect and measure the water drained is present. The weight measurement was done daily by a balance with a resolution of $100 \mathrm{~g}$ (Figure 3) and with a load cell that collect the data every $30 \mathrm{~min}$ to a data logger.

Daily weight data was collected and no drainage water was observed from the bottom of the lysimeters. Runoff was considered equal to zero because of the flat lying of the land. Daily crop evapotranspiration (ETm, in $\mathrm{mm})$ was calculated as:

$$
E T_{m}=\frac{\left(W L_{i}-W L_{i-1}\right)}{4}-R_{i-1}
$$

where $W_{L i}$ and $W L_{i-1}$ are the lysimeter weights at day $i$ and $i-1$ respectively in $\mathrm{kg}$, and $R$ is the rain in $\mathrm{mm}$. Average values of two lysimeters were used. 
During the field experiment, climatic data were measured by a standard meteorological station, located on a grass cover situated near the experimental field. Maximum and minimum temperatures, global solar radiation, precipitation, wind speed and relative maximum and minimum air humidity were collected with daily frequency.

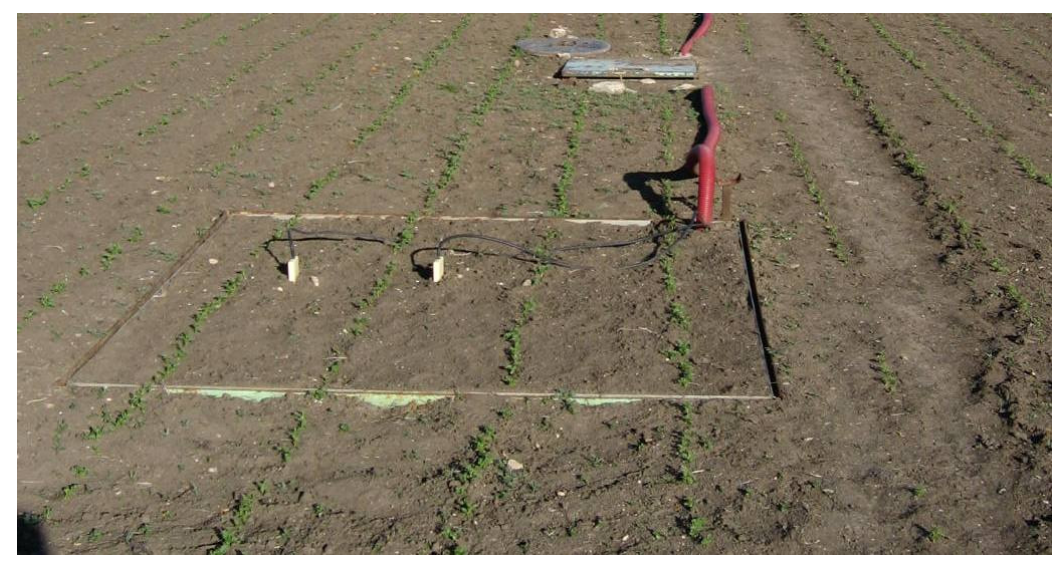

Figure 2: $\quad$ Lysimeter during field chickpea experiment in the year 2006-07.

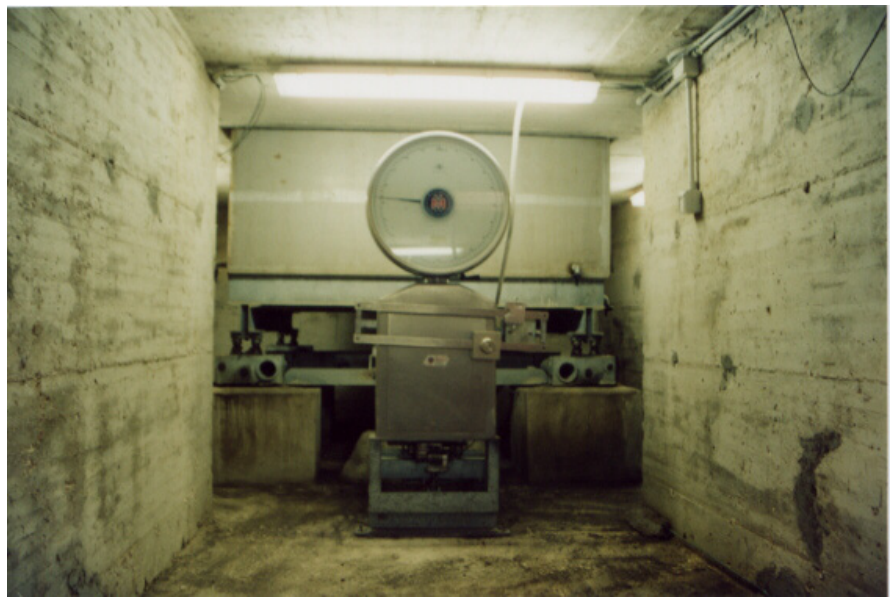

Figure 3: Lysimeter weighing equipment situated under soil surface.

Chickpeas (cv Pascià, Desi type), were sown in the 1 ha size field on $4^{\text {th }}$ December 2006, at a density of 40 seed $\mathrm{m}^{-2}$, with a distance between rows of $0.5 \mathrm{~m}$. A single irrigation supply of $60 \mathrm{~mm}$ was applied at flowering, 137 days after sowing. To ensure uniform water distribution, a drip irrigation system was 
used, with one line for each plant row and drippers of $4 \mathrm{~L} \mathrm{~h}^{-1}$ flow. A water flow meter was placed at the head of each plot to measure accurately the amount of irrigation water supplied. A pre-sowing fertilisation with $60 \mathrm{~kg} \mathrm{ha}^{-1}$ of $\mathrm{P}_{2} \mathrm{O}_{5}$ as triple perphosphate was applied.

Harvest was performed with a plot machine harvester, on $4^{\text {th }}$ July 2007 , when the seed moisture content was lower than $13 \%$. The main crop phenological phases were recorded in all the plots and expressed as degree days (GDD), considering a base temperature of $0^{\circ} \mathrm{C}$ [7].

Soil moisture was measured at 1-hour time with TDR (Time Domain Reflectometer, Campbell Scientific INC) probes (25 cm length), placed vertically in the soil at $-30,-60$, and $-90 \mathrm{~cm}$ depth, after plants emergence. Gravimetric soil water measurement were also carried out at $-20,-40$ and $-60 \mathrm{~cm}$ depth at sowing, at harvest and at growth analysis sampling dates.

Growth analysis was carried out from March to June; at seven sampling dates, dry matter, separated into stems, green and dead leaves and pods was measured by taking 0.5 linear meter sample from four samples in the field and dried at $80^{\circ} \mathrm{C}$ until weight was constant. Green Area Index was determined measuring green leaves area with Delta $\mathrm{T}$ Devices (Decagon Devices Inc., WA, USA). Fraction canopy cover (\%) was calculated with Beer's law, as:

$$
C C=1-\exp (-e c * G A I * C f)
$$

where: $e c$ is the extinction coefficient and equal to $0.817, G A I$ is the green leaf area and $C f$ is the clumping factor and equal to 0.75 .

Crop coefficients were calculated as the ratio between the crop evapotranspiration measured by lysimeters $(E T m)$ and the reference evapotranspiration $\left(E T_{0}\right)$ calculated by mean of Penman-Monteith formula. Comparison between values obtained by this research and those reported by FAO Paper 56 was done.

\section{Results and discussion}

The climatic behaviour during the chickpea crop cycle is shown in fig. 4, reporting the comparison between the 2006-07 season and long term average cumulate rainfall, daily $E T_{0}$, maximum and minimum air temperatures. It can be observed as the maximum temperature reached often peaks of $4-5^{\circ} \mathrm{C}$ greater than the long term average, during all growing crop cycle.

In fig. 5 the daily pattern of $E T_{0}$ and crop evapotranspiration measured by lysimeter $(E T m)$ are reported, highlighting as the ETm follows the typical pattern of the crop fraction canopy cover. During the first part of the crop cycle, from sowing to the beginning of exponential crop growth, the ETm oscillated between 0.5 and $1.6 \mathrm{~mm} \mathrm{~d}^{-1}$. The highest values of ETm were observed on reaching maximum canopy cover with daily values ranging between 5.0 and $7.5 \mathrm{~mm} \mathrm{~d}^{-1}$. One irrigation occurred halfway through April (136 days after sowing), and this is evident in fig. 5, showing values of ETm of about 5.6-6.0 $\mathrm{mm} \mathrm{d}^{-1}$ for several days. 

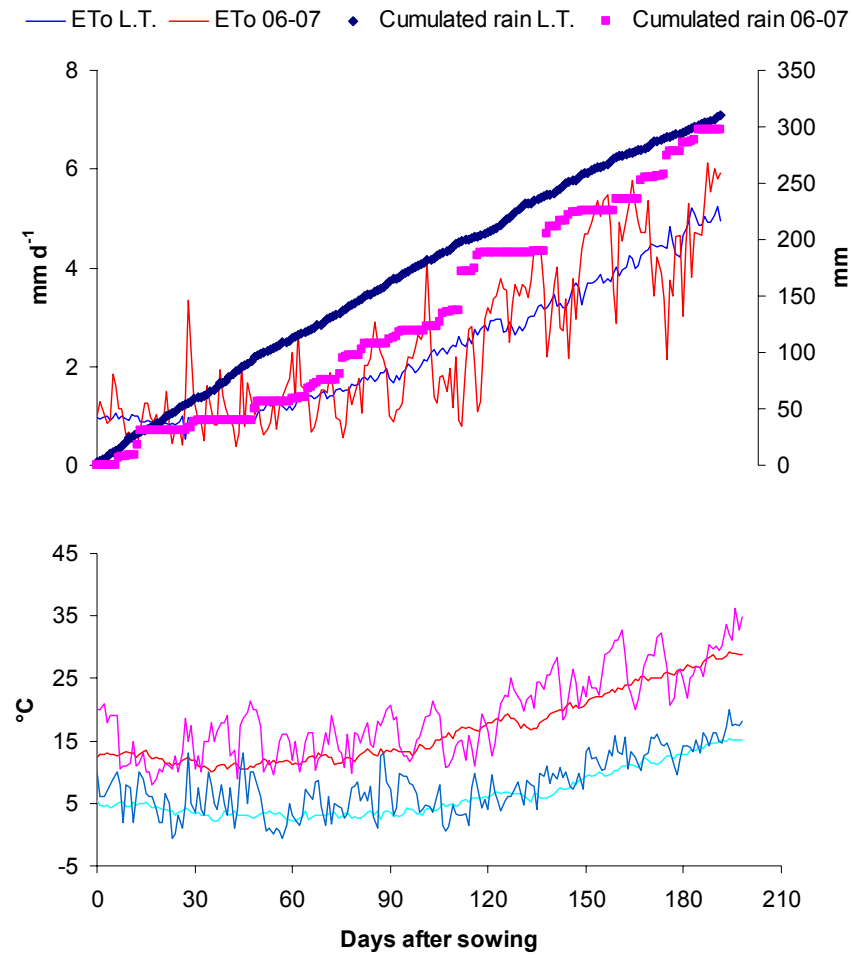

—T max L.T. —T $\max 06-07 — \mathrm{~T} \min$ L.T. —T $\min 06-07$

Figure 4: Comparison among some recorded climatic variables during the chickpea crop cycle and averages of long term (50 years).

The maximum values of water consumed by the crop were observed in correspondence of maximum fraction canopy cover, between the flowering and early seed filling stages, reaching the highest values recorded during all crop growth cycles. After this growing stage, there was a rapid decline of the crop water consumption, copying the pattern of canopy cover, which rapidly decreases after the attainment of maximum value (Fig. 5).

The crop coefficients calculated during crop cycle, can be divided into four segments (Fig. 6); the first part includes the initial $K c\left(K c_{i n i}\right)$ from sowing to $20 \%$ of canopy cover. The length of this phase is 85 days and the relative value is 0.54 . The second part of the segment includes the crop development stage, from $20 \%$ to $45 \%$ of the canopy cover, with a length of 35 days. The third part of segment is relative to the mid-season $\left(K c_{m i d}\right)$ phase, with a length of 40 days and a value of 0.97 . Finally, the late season stage persists for 35 days, with a $K c_{\text {end }}$ value equal to 0.29 (Tab. 1).

Unfortunately, the FAO Paper 56, does not report the duration of growing cycle stages for the chickpea, but only the $K c$ values for the mid-stage and late- 


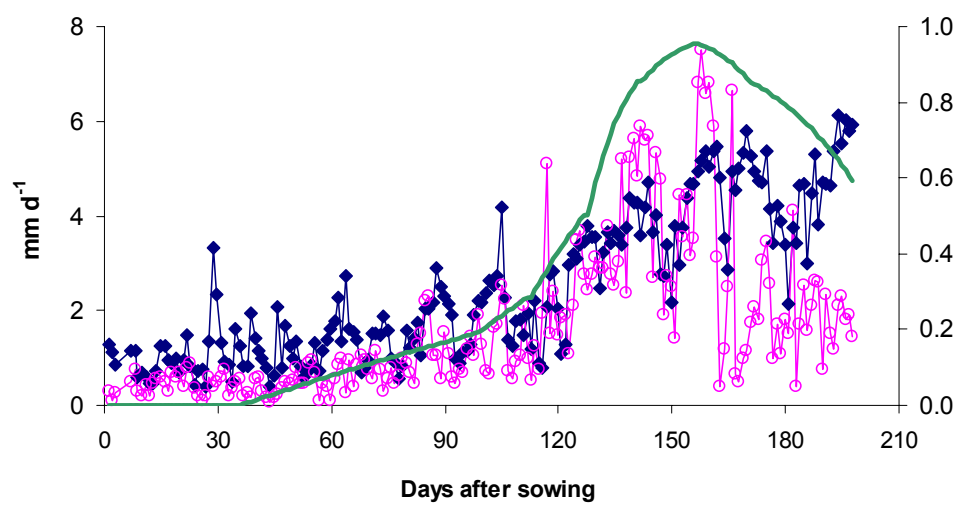

Figure 5: Daily reference evapotranspiration ( $E T_{0}$, solid symbols), crop evapotranspiration (ETm, circle symbols) and fraction canopy cover during chickpea crop growth cycle (line).

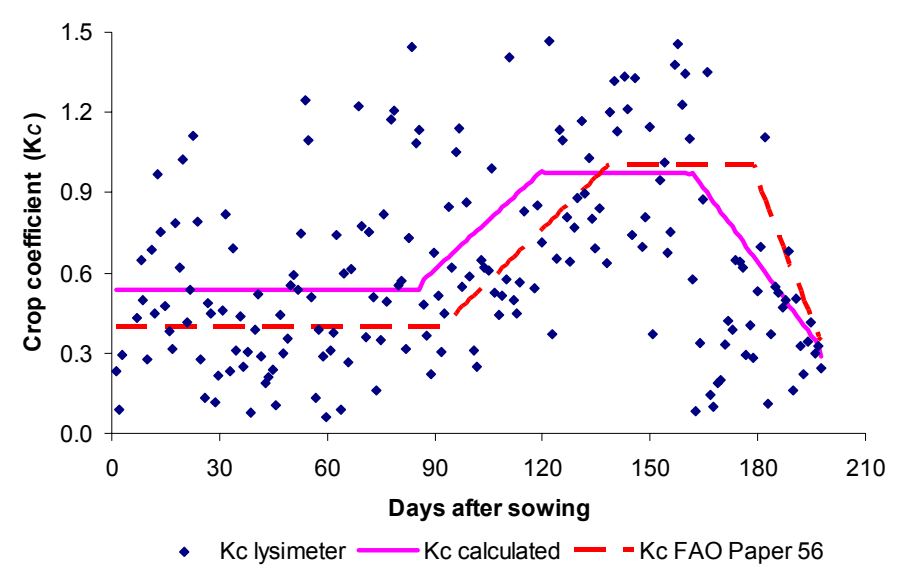

Figure 6: Daily crop coefficient calculated by means of lysimeters (symbols), interpolation of calculated (solid line) and FAO crop coefficients (dashed line).

stage. For this reason, a comparison between ours observed duration of crop cycle, can be done only with a similar legume crop cultivated in a similar environment and in the same sowing period, in this case a broad bean dry. Overestimation in the first crop stage and underestimation in the last stage are the mostly noticeable differences for the determined experimentally $K c$ versus the proposed by FAO ones (Tab. 1).

Cumulated evapotranspiration at the end of crop cycle was $323 \mathrm{~mm}$, whereas that calculated with $\mathrm{FAO}$ values was $358 \mathrm{~mm}$, with an overestimation equal to 
$10.8 \%$ (Fig. 7) due to the underestimation of water requirement during the second and third crop phenology stages.

Fig. 8a shows the behaviour of crop evapotranspiration, following rainfall and irrigation events, but it was high especially after the green leaf area index reached a value of about $2.5 \mathrm{~m}^{2} \mathrm{~m}^{-2}$ (Fig. $8 \mathbf{b}$ ). The total plant dry matter accumulation resulted very slowly during the first 120 days after sowing, but with the arising temperature during spring, the exponential growth phase occurred in the period with high ETm and higher $K c$ estimated values $\left(K c_{\text {mid }}=\right.$ 0.97 , from 119 to 158 days after sowing).

Table 1: Duration and evapotranspiration crop coefficients $(K c)$ for chickpeas deriving from FAO n. 56 paper and measured in this experiment.

\begin{tabular}{|c|c|c|c|}
\hline & Crop growth stage & $\begin{array}{c}\text { Lenght } \\
\text { (days) }\end{array}$ & Kc \\
\hline FAO n. 56 paper & & & \\
\hline & initial & $90^{*}$ & $0.4^{*}$ \\
\hline & development & $45^{*}$ & from 0.4 to 1.0 \\
\hline & mid-season & $40^{*}$ & 1.0 \\
\hline & late season & $20^{*}$ & from 1.0 to 0.35 \\
\hline From this experiment & & & \\
\hline & & & 0.54 \\
\hline & initial & 85 & from 0.54 to 0.97 \\
\hline & development & 35 & 0.97 \\
\hline & mid-season & 40 & from 0.97 to 0.29 \\
\hline
\end{tabular}

* Values derived from those reported for dry broad bean.

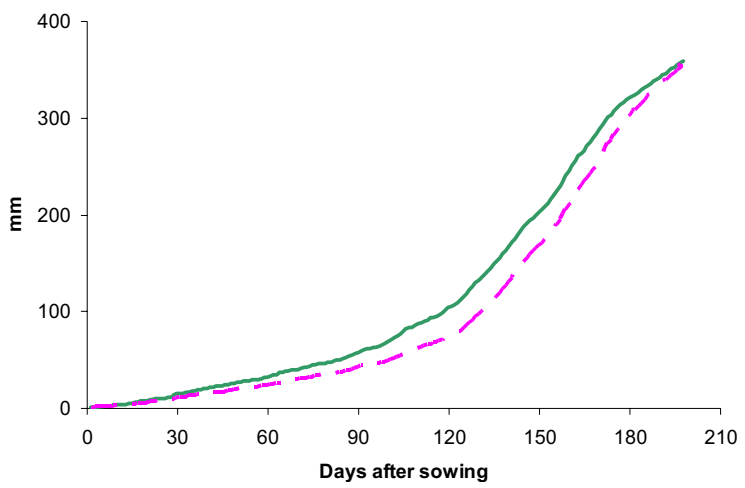

Figure 7: Comparison between the cumulated crop evapotranspiration, calculated with experimentally obtained $K c$ (solid line) and with that proposed by the FAO Paper 56 ones (dashed line). 

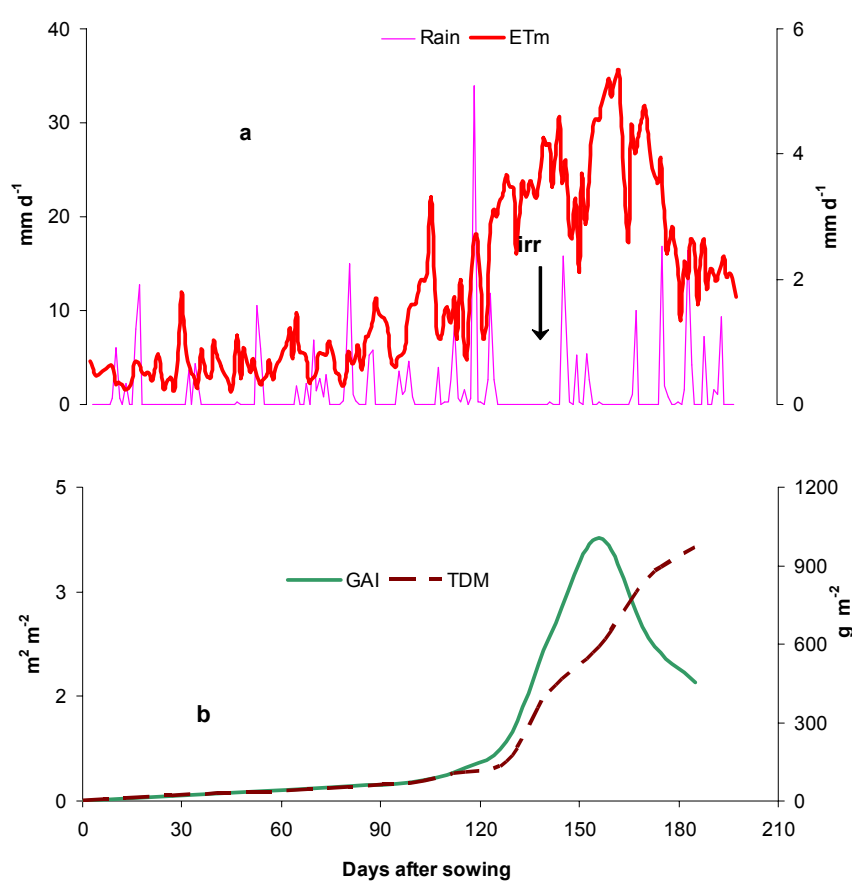

Figure 8: $\quad$ Crop evapotranspiration $(E T m)$, daily rainfall and irrigation (a), total plant dry biomass and green leaf area index (b) observed during chickpea growth cycle.

\section{Conclusions}

From the current research on chickpeas, the length of different phenological stages and relative $K c$ can be furnished for winter chickpeas in a Mediterranean environment with a good fertility soil. In particular, more precise evaluation of the different stages and $K c$ values have been calculated in order to allow water saving, especially in the water-limited environment. The FAO Paper 56 can be updated with this information relative to the chickpea crop and especially for what concerns the different crop length stages.

\section{References}

[1] FAOSTAT, 2008. http://faostat.fao.org/site/612/default.aspx\#ancor

[2] Zhang, H., Pala, M., Oweis, T. and Harris, H., Water use and water use efficiency of chickpea and lentil in a Mediterranean environment. Aust. J. Agric. Res. 51: pp. 259-304, 2000.

[3] Rinaldi, M., Vonella, A.V., Soldo, P., Debiase, G., Garofalo, P., Yield and canopy response of chickpea (Cicer arietinum L.) to different irrigation 
regimes. In "Sustainable Irrigation - Management, Technologies and Policies IT', Y. Villacampa Esteve, C.A. Brebbia \& D. Pratas Rico (Editors), WIT Press (UK), WIT Transaction on Ecology and the Environment, vol. 112, pp. 123-132, 2008.

[4] Doorenbos, J., and W. O. Pruitt, 1977. Crop water requirements. Irrig. and Drain. Paper 24, Food and Agric. Organization of the United Nations, Rome, Italy. 144 pp, 1977.

[5] Allen, R.B., L.S. Pereira, D. Raes, and M. Smith, Crop evapotranspiration. Irrig. and Drain. Paper 56, Food and Agric. Organization of the United Nations, Rome, Italy. 300 pp, 1998.

[6] Rana, G., Katerij, N., Measurement and estimation of actual evapotranspiration in the field under Mediterranean climate: a review. Eur. J. of Agronomy 13, pp. 125-153, 2000.

[7] Ellis, R.H., Covell, S., Roberts, E.H. and Summerfield, R.J., The influence of temperature on seed germination rate in grain legumes. II. Interspecific variation in chickpea (Cicer arietinum L.) at constant temperatures. J. Exp. Bot. 37, pp. 1503-1515, 1986. 